\title{
Immunomodulatory and Antioxidative potentials of adipose-derived Mesenchymal stem cells isolated from breast versus abdominal tissue: a comparative study
}

Nourhan Abu-Shahba ${ }^{1,2^{*}}$, Marwa Mahmoud ${ }^{1,2}$, Mazen Abdel-Rasheed ${ }^{1,3}$, Yasmine Darwish ${ }^{4}$, Ahmad AbdelKhaliq ${ }^{4}$, Eman Mohammed ${ }^{1,2}$, Mahmoud ElHefnawi ${ }^{5}$ and Osama Azmy ${ }^{1,3}$

\begin{abstract}
Background: Adipose-derived stem cells (ASCs) are considered ideal candidates for both research and cellular therapy due to ease of access, large yield, feasibility, and efficacy in preclinical and clinical studies. Unlike the subcutaneous abdominal fat depot, breast ASCs features are still not well recognized, limiting their possible therapeutic use. ASCs were found to exert immunomodulatory and antioxidative activities for maintaining homeostasis and functionality of diseased/damaged tissues. This study aims to investigate the immunomodulatory and antioxidative potentials of breast versus abdominal isolated ASCs to find out which anatomical site provides ASCs with better immunoregulatory and oxidative stress resistance capabilities.
\end{abstract}

Methods: ASCs were isolated from abdominal and breast tissues. Gene expression analysis was conducted for a panel of immunomodulatory and antioxidative genes, as well as adipokines and proliferation genes. Flow cytometric analysis of a group of immunomodulatory surface proteins was also performed. Finally, the significantly expressed genes have undergone protein-protein interaction and functional enrichment in silico analyses.

Results: Our results revealed similar morphological and phenotypic characteristics for both breast and abdominal ASCs. However, a significant elevation in the expression of two potent immunosuppressive genes, IL-10 and IDO as well as the expression of the multifaceted immunomodulatory adipokine, visfatin, was detected in breast versus abdominal ASCs. Moreover, a significant overexpression of the antioxidative genes, GPX1, SIRT5, and STAT3 and the proliferation marker, Ki67, was also observed in breast ASCs relative to abdominal ones. In silico analysis showed that both of the differentially upregulated immunomodulatory and antioxidative mediators integratively involved in multiple biological processes and pathways indicating their functional association.

(Continued on next page)

\footnotetext{
* Correspondence: nm.diaa@nrc.sci.eg; nourajina@hotmail.com

'Stem Cell Research Group, Centre of Excellence for Medical Research, National Research Centre, Cairo, Egypt

${ }^{2}$ Medical Molecular Genetics Department, Human Genetics and Genome Research Division, National Research Centre, Cairo 12622, Egypt

Full list of author information is available at the end of the article
}

\section{Springer Open}

(c) The Author(s). 2020 Open Access This article is licensed under a Creative Commons Attribution 4.0 International License which permits use, sharing, adaptation, distribution and reproduction in any medium or format, as long as you give appropriate credit to the original author(s) and the source, provide a link to the Creative Commons licence, and indicate if changes were made. The images or other third party material in this article are included in the article's Creative Commons licence, unless indicated otherwise in a credit line to the material. If material is not included in the article's Creative Commons licence and your intended use is not permitted by statutory regulation or exceeds the permitted use, you will need to obtain permission directly from the copyright holder. To view a copy of this licence, visit http://creativecommons.org/licenses/by/4.0/. The Creative Commons Public Domain Dedication waiver (http://creativecommons.org/publicdomain/zero/1.0/) applies to the data made available in this article, unless otherwise stated in a credit line to the data. 
(Continued from previous page)

Conclusion: Breast ASCs possess superior immunomodulatory and antioxidative capabilities over abdominal ASCs. Our findings shed light on the possible therapeutic applications of breast ASCs in immune-related and oxidative stressassociated diseases.

Keywords: Adipose-derived stem cells (ASCs), Breast adipose tissue, Abdominal adipose tissue, Immunomodulatory potential, Antioxidative potential

\section{Background}

Adipose tissue is a connective tissue composed mainly of adipocytes, in addition to preadipocytes, fibroblasts, pericytes, vascular endothelial cells, immune cells, and mesenchymal stem cells (MSCs) (Waki and Tontonoz 2007; Han et al. 2015). Moreover, it acts as a bioactive endocrine organ that secretes soluble factors (Tchkonia et al. 2013). There are two major types of fat: visceral fat and subcutaneous fat (Wronska and Kmiec 2012). Subcutaneous fat represents the largest fat depot in the human body (Abate et al. 1995), containing various subcutaneous fat depots classified according to their anatomical locations. These depots comprise a multipotent mesenchymal stem cell population, known as adipose-derived stem cells (ASCs) (Schipper et al. 2008). ASCs represent one of the most promising stem cell populations due to their ease of access, large yield, being obtained through minimal invasive procedures in addition to their high proliferative and multilineage potentials (Zuk et al. 2001; Locke et al. 2009; O'Halloran et al. 2017). Moreover, ASCs were recommended as good candidates for cellular therapy as they have shown feasibility and efficacy in preclinical and clinical studies (O'Halloran et al. 2017; Gimble et al. 2007; Mizuno et al. 2012).

Recently, several comparative reports have demonstrated that the biological and functional characteristics of ASCs differ according to the site of harvest (Schipper et al. 2008; Hanson et al. 2013; Russo et al. 2014; Nepali et al. 2018). ASCs harvested from superficial abdominal regions exerted higher antiapoptotic action than those harvested from the arm, thigh, trochanteric, and deep abdominal depots (Schipper et al. 2008). Additionally, ASCs derived from orbit showed elevated adipogenic and osteogenic differentiation potential and lower chondrogenic potential relative to abdominal ASCs (Nepali et al. 2018), while the amount of ASCs harvested from abdomen seemed to be higher than that of the hip and thigh regions (Jurgens et al. 2008). Furthermore, breastisolated ASCs showed higher expression of FGF2 (fibroblast growth factor 2) (Hanson et al. 2013) and was highly enriched in MSCs expressing SSEA-4 (stage-specific embryonic antigen 4) compared to abdominal ASCs (Maddox et al. 2012).

The subcutaneous abdominal fat depot is nearly the most commonly used depot for ASCs harvesting due to its abundance in patients (Schipper et al. 2008; Jurgens et al. 2008; Padoin et al. 2008). However, other fat depots are emerging as possible alternative sources for ASCs (Nepali et al. 2018; Maddox et al. 2012; Rezai Rad et al. 2017) such as breast. Breast fat depot is one of the recently identified ASCs sources; however, little concern has been given to this source. Breast ASCs characteristics are still not clear, limiting their possible therapeutic use (Yang et al. 2014).

ASCs were found to exert several paracrine actions that are essential for homeostatic restoration and proper functionality in diseased/damaged tissues, including the immunomodulatory and antioxidative actions (Liang et al. 2014; Kim et al. 2015; Orgun and Mizuno 2017). The immunomodulatory potential is mediated through secretion of a variety of cytokines which impact different immune cells activities (Leto Barone et al. 2013). This immunoregulatory role had found application in both preclinical and clinical studies of different immunerelated diseases such as rheumatoid arthritis, Crohn's disease, graft versus host disease, and diabetes (Maria et al. 2016). ASCs antioxidative action acts against the accumulation of the reactive oxygen species (ROS) that induce various diseases (Liang et al. 2014), such as neurodegenerative, cardiovascular diseases, and endometriosis (Uttara et al. 2009; Scutiero et al. 2017). Moreover, ASCs were found to alleviate inflammation in the injured areas through both their antioxidative and antiinflammatory properties (Kim et al. 2015).

Identifying the influence of different fat depots on ASCs characteristics could be essential for developing new cell-based therapeutic strategies. This study aimed to compare between ASCs isolated from two different anatomical sites, to detect which fat depot provides ASCs with more enhanced immunomodulatory and/or antioxidative potential. This would unravel the type of ASCs that would be more suitable for therapeutic application in immune disturbance and/or oxidative stressinduced pathologies.

\section{Methods}

Isolation of abdominal and breast adipose-derived mesenchymal stem cells

Abdominal adipose tissue samples $(n=7)$ were obtained from subjects undergoing either abdominoplasty or 
incisional hernia surgeries, while breast adipose tissue samples $(n=7)$ were obtained from subjects undergoing reduction mammaplasty surgeries after taking informed consent. The study participants aged between 22 and 55 years. The sample collection was ethically approved by the Medical Research Ethics Committee, the National Research Centre, Cairo, Egypt (Registration code: 16282). Both abdominal and breast ASCs were isolated according to the previously described protocol of Bunnel et al. (Bunnell et al. 2008) with some modifications. The excised fat was dissected using sterile blades and washed in phosphate-buffered saline (PBS, Lonza, Belgium) and then digested with $1 \mathrm{mg} / \mathrm{ml}$ type $1 \mathrm{~A}$ collagenase (Gibco Life Technologies, USA). The digested tissue underwent centrifugation, resuspension in PBS, and filtration through $100 \mu \mathrm{m}$ nylon mesh cell strainer (Greiner BioOne, Germany). The cell filtrate was centrifuged, resuspended, and cultured in complete growth media comprising Dulbecco's Modified Eagle Medium (DMEM, Lonza, USA) supplemented with $10 \%$ fetal bovine serum (FBS, Lonza, Belgium), 2\% penicillin/streptomycin/ amphotericin (Lonza, USA), and 1\% Glutamax (Gibco, Life Technologies, USA). Cultured cells were incubated in a $5 \% \mathrm{CO}_{2}$ humidified atmosphere at $37^{\circ} \mathrm{C}$. Nonadherent cells were removed with the first media exchange. Media exchange was done twice a week and cells were passaged at a $75-80 \%$ confluence.

\section{Morphological identification of isolated ASCs}

The typical spindle fibroblast like morphology and plastic adherence features of MSCs were examined using an inverted microscope (Leica Microsystems DMil, Switzerland) equipped with an imaging system (Leica DMS300, Switzerland). Cell morphology and expansion were followed up and photographed through different passages.

\section{Characterization of ASCs by flow cytometry}

The expression of ASCs characteristic surface markers was analyzed by flow cytometry technique, for abdominal and breast ASCs, as previously described (Fathi and Farahzadi 2018; Fathi et al. 2019) with some modifications. At the second or third passage, a total of $5 \times 10^{4}$ cells were harvested, enzymatically using $0.25 \%$ TrypsinEDTA (Lonza) or manually using a cell scraper, centrifuged at $1600 \mathrm{rpm}$, and then washed with PBS (Lonza). Cells were incubated for $20-30 \mathrm{~min}$ in the dark with the suitable volumes of the following fluorochrome-labeled monoclonal antibodies: CD90-FITC, CD105-PE, CD44$\mathrm{PE}$, and CD34-FITC (BD, Biosciences, USA). After incubation, another washing step was done using PBS to remove excess stain. Flow cytometric analysis was performed using a Coulter EPICS device (Beckman Coulter, USA) and data analysis was carried out using System II Software.

\section{Real time PCR gene expression analysis}

Total RNA was isolated from abdominal and breast ASCs at the second or third passage using the miRNeasy Mini Kit for efficient RNA isolation (Qiagen, USA) following the manufacturer's instructions. Briefly, $1.5 \times 10^{6}$ cells were homogenized in QIAzole reagent (Qiagen, USA), mixed with chloroform, and then centrifuged. The upper aqueous phase was obtained and mixed with absolute alcohol and then transferred into the kit separation column in which several washing steps were performed using the kit reagents. Finally, RNA was dissolved in RNase-free water. RNA quantification was performed using a NanoDrop 2000 spectrophotometer (Thermo Fisher Scientific, USA). cDNA was synthesized from $1 \mu \mathrm{g}$ of extracted RNA using Revert Aid First Strand cDNA Synthesis Kit (Thermo Fisher Scientific, Lithuania). TaqMan gene expression assays (Thermo Fisher Scientific, USA) for the following immunomodulatory mediators: interleukin 10 (IL-10), indoleamine-2, 3-dioxygenase (IDO), interleukin 6 (IL-6), tumor necrosis factor (TNF), and TNF $\alpha$-stimulated gene 6 (TSG-6), and the following adipokines: leptin, resistin, adiponectin, and visfatin, were used as instructed by the manufacturer. Beta-actin was used as a housekeeping gene for normalization (Table 1A).

QuantiTect SYBR Green Master Mix Kit (Qiagen, USA) was employed for gene expression analysis of the following antioxidative mediators: superoxide dismutase 1 (SOD1), superoxide dismutase 2 (SOD2), catalase (CAT), glutathione peroxidase 1 (GPX1), sirtuin 3 , sirtuin 4, sirtuin 5 (SIRT3-5), and the proliferation marker Ki67/MKI67. QuantiTect predesigned primer assays (Qiagen, USA) for the aforementioned genes were utilized (Table 1B). The following primers were used for the pluripotency and antioxidative transcription factor; STAT3:5' -ATCGAGCAGCTGACTACACTG-3' and 5'-ATCGAGCAGCTGACTACACTG-3'. Melting point analysis was done to ensure the specificity of the amplification product. GAPDH was used as a housekeeping gene for normalization. Plates were read using the ABI 7500 fast system (Applied Biosystems). The gene expression data were analyzed using the comparative $\Delta \Delta \mathrm{Ct}$ method (Livak and Schmittgen 2001).

\section{Flow cytometric analysis of immunoregulatory cell surface proteins}

The surface expression of immunoregulatory-related molecules was evaluated for ASCs, at the second or third passage, by flow cytometric analysis using the following fluorochrome-labeled monoclonal antibodies: CD200PE, CD271-PE, CD274-FITC, and CD276-FITC (BD, Biosciences, USA). Flow cytometry was performed using a Beckman Coulter EPICS XL device (Beckman Coulter, 
Table 1 (A) Gene expression TaqMan probes (Thermo Fisher Scientific, USA) and (B) predesigned QuantiTect primer assays (Qiagen, USA)

\begin{tabular}{|c|c|}
\hline \multicolumn{2}{|c|}{ (A) Taqman Probes used for real time-PCR assay } \\
\hline Probes & $\begin{array}{l}\text { Taqman transcript assay accession } \\
\text { number }\end{array}$ \\
\hline interlukin-10 (IL-10) & Hs00961622_m1 \\
\hline $\begin{array}{l}\text { indoleamine-2,3-dioxygenase } \\
\text { (IDO) }\end{array}$ & Hs00984148_m1 \\
\hline interlukin-6 (IL-6) & Hs00174131_m1 \\
\hline tumor necrosis factor (TNF) & Hs00174128_m1 \\
\hline $\begin{array}{l}\text { TNFa-stimulated gene } 6 \\
\text { (TSG6) }\end{array}$ & Hs00200180_m1 \\
\hline leptin & Hs00174877_m1 \\
\hline adiponectin & Hs00605917_m1 \\
\hline resistin, & Hs00220767_m1 \\
\hline visfatin & Hs00237184_m1 \\
\hline b-actin & Hs01060665_g1 \\
\hline \multicolumn{2}{|c|}{ (B) Quantitect human primer assays used for real time-PCR } \\
\hline Primer assays & Accession Number \\
\hline $\begin{array}{l}\text { superoxide dismutase } 1 \\
\text { (SOD1) }\end{array}$ & (QT01671551) \\
\hline $\begin{array}{l}\text { superoxide dismutase } 2 \\
\text { (SOD2) }\end{array}$ & (QT01008693) \\
\hline $\begin{array}{l}\text { glutathione peroxidase } \\
1 \text { (GPX1) }\end{array}$ & (QT00203392) \\
\hline catalase (CAT) & (QT00079674) \\
\hline sirtuin 3 (SIRT3) & (QT00091490) \\
\hline sirtuin 4 (SIRT4) & (QT00202503) \\
\hline sirtuin 5 (SIRT5) & (QT00047537) \\
\hline Ki67 (MKi67) & (QT00014203) \\
\hline GAPDH & (QT00079247) \\
\hline
\end{tabular}

USA) and data analysis was carried out using System II software.

\section{Bioinformatics analysis}

Protein-protein interaction (PPI) and functional enrichment in silico analyses were performed for our significantly upregulated gene set in breast ASCs versus abdominal ASCs (IL-10, IDO, NAMPT, GPX1, SIRT5, STAT3, and ki67/MKI67), using the STRING server, https://string-db.org/ (Szklarczyk et al. 2019), to find out how these genes interact together. Moreover, gene enrichment functional analysis was done to detect the pathways and the biological processes that our genes contribute to. Moreover, functional association gene network prediction analysis was performed using the GeneMANIA server, http://genemania.org/, for the indicated gene set (Franz et al. 2018) to explore the possible gene networks functionally associated with our target genes.

\section{Statistical analysis}

Statistical analysis was carried out using SPSS 16.0 (IBM, New York, USA) for the obtained results by using the independent $t$-test and the Mann-Whitney $U$ test. Statistical differences between the abdominal and breast ASCs groups were considered significant at $p$-values less than 0.05 .

\section{Results}

Both breast and abdominal ASCs exhibiting comparative morphological and phenotypic characteristics

The identity of both abdominal and breast ASCs was detected by morphological examination and phenotypic analysis. Both types of ASCs were plastic adherent with typical mesenchymal stem cell morphology as shown under the inverted microscope (Fig. 1). Flow cytometric phenotypic analysis has revealed that ASCs of both abdominal and breast tissues were positive for the MSC characteristic markers, CD90, CD105 and CD44, and negative for the hematopoietic marker, CD34 with no statistical difference between both types of ASCs ( $p$ value $>0.05$ ) (Fig. 2).

\section{Upregulation of immunoregulatory/anti-inflammatory mediators in breast versus abdominal ASCs}

Expression levels of the tested panel of immunomodulatory and adipokine genes have shown upregulation of these genes in breast ASCs compared to abdominal ASCs, some of which were significantly elevated. Two important immunosuppressive genes (IL-10 and IDO) were found significantly elevated in breast ASCs relative to abdominal cells ( $p$-values 0.048 and 0.025 , respectively). Visfatin adipokine was found also to be significantly upregulated in breast ASCs ( $p$-value 0.018) (Fig. 3a). TNF, IL-6, TSG-6, and leptin expression levels were elevated in breast versus abdominal ASCs; however, this elevation did not reach statistical significance. Adiponectin and resistin expression was undetermined in most samples.

Upregulation of antioxidative, pluripotency, and proliferation markers in breast versus abdominal ASCs Gene expression analysis also revealed the upregulation of all antioxidative, pluripotency, and proliferation mediators in breast ASCs relative to abdominal ones, with significant elevation in some genes. Breast ASCs constitutively expressed GPX1 ( $p$-value 0.003) and SIRT5 ( $p$ value 0.013) compared to abdominal ASCs. Expression of SOD2 and SIRT3 was significantly upregulated in five out of seven breast ASCs cultures ( $p$-value 0.042 for both). The antioxidative enzymes CAT, SOD1 and SIRT4 showed non-significant upregulation in breast ASC populations indicating comparable gene levels. Moreover, significant elevation was detected for the pluripotency and antioxidative transcription factor, 

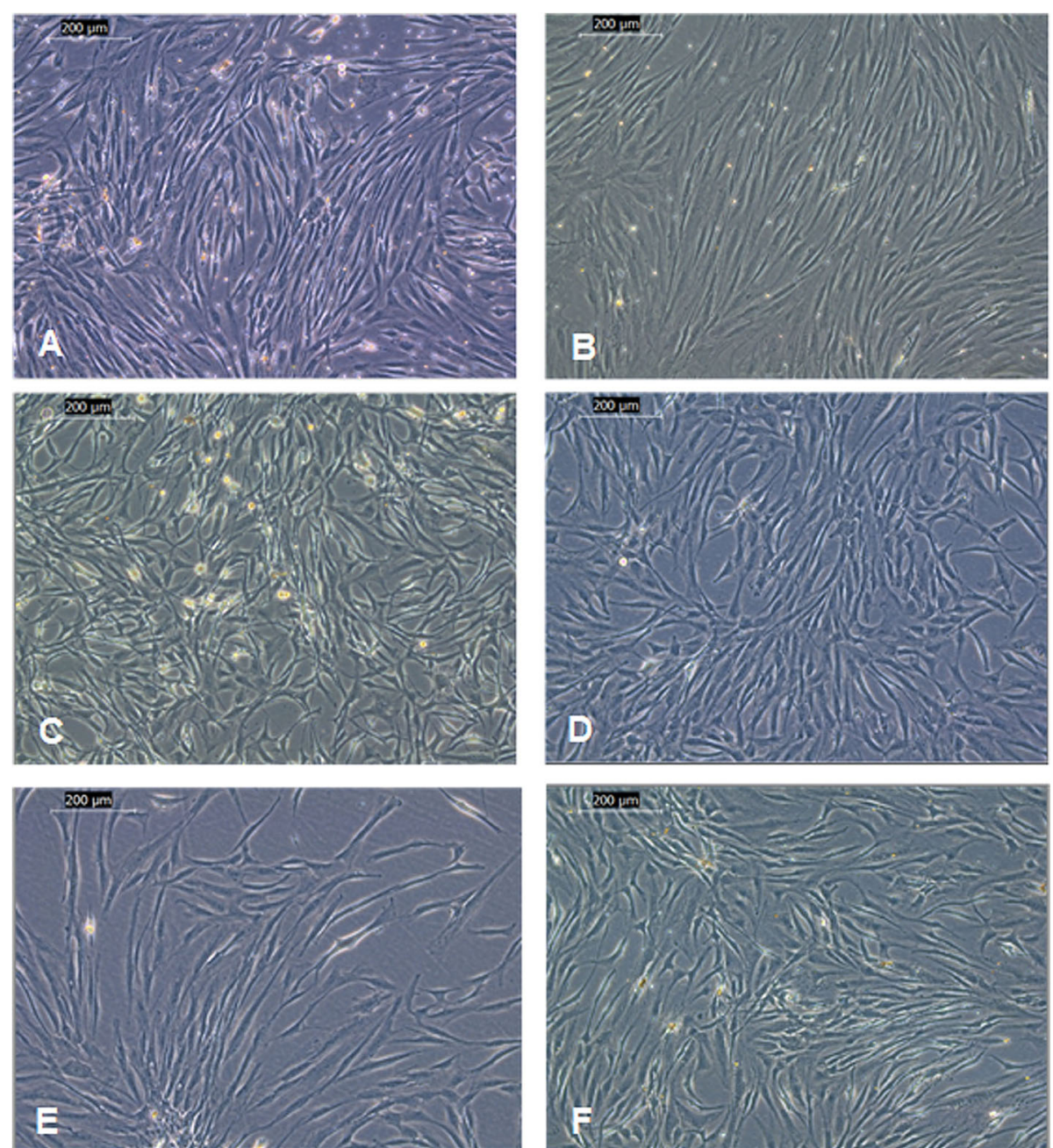

Fig. 1 Morphology of abdominal and breast ASCs at different passages. a, c, and e Abdominal ASCs at passages 0, 1, and 2, respectively. b, d, and $\mathbf{f}$ Breast ASCs at passages 0, 1, and 2, respectively. Cells of both types of tissues appear with typical MSCs spindle morphology (scale bar = 200 $\mu \mathrm{m})$

STAT3 ( $p$-value 0.025), as well as the proliferation marker Ki67 ( $p$-value 0.006) that was highly significant in breast compared to abdominal ASCs supporting the observed superior in vitro expansion potential of breast ASCs population (Fig. 3b).

\section{Comparative expression of immunoregulatory surface proteins in breast and abdominal ASCs}

Flow cytometric cell surface expression of immunoregulatory surface molecules has shown comparable results for the tested surface molecules in abdominal and breast ASCs where no significant difference was detected ( $p$ value $>0.05$ ). The mean expression percentage of CD200 was $59.7 \pm 4.2 \%$ in abdominal ASCs and $59.3 \pm 6.2 \%$ in breast ASCs; CD271 expression was $20.1 \pm 2.9 \%$ in abdominal ASCs and $14.3 \pm 3.9 \%$ in breast CD274 was $32.7 \pm 7.2 \%$ in abdominal ASCs and $48 \pm 12.3 \%$ in breast
ASCs; CD276 was $86.2 \pm 2.9 \%$ in abdominal ASCs and $84.6 \pm 3.4 \%$ in breast ASCs (Fig. 4).

\section{Significantly expressed immunomodulatory and antioxidative mediators in breast ASCs acting integratively in various vital biological processes and pathways}

PPI and functional enrichment analysis were performed using the STRING server for our differentially upregulated genes in breast versus abdominal ASCs. It was demonstrated shown that members of this set exhibited a significant PPI enrichment with $p$-value of 0.0008 .7 (Fig. 5). A strongly evidenced interaction between IL-10 and STAT3 was indicated by experimental, database annotation, and automated text-mining evidence. Also, NAMPT and SIRT5 showed another strongly evidenced interaction as indicated by experimental and automated text-mining and predicted gene neighborhood evidence. 


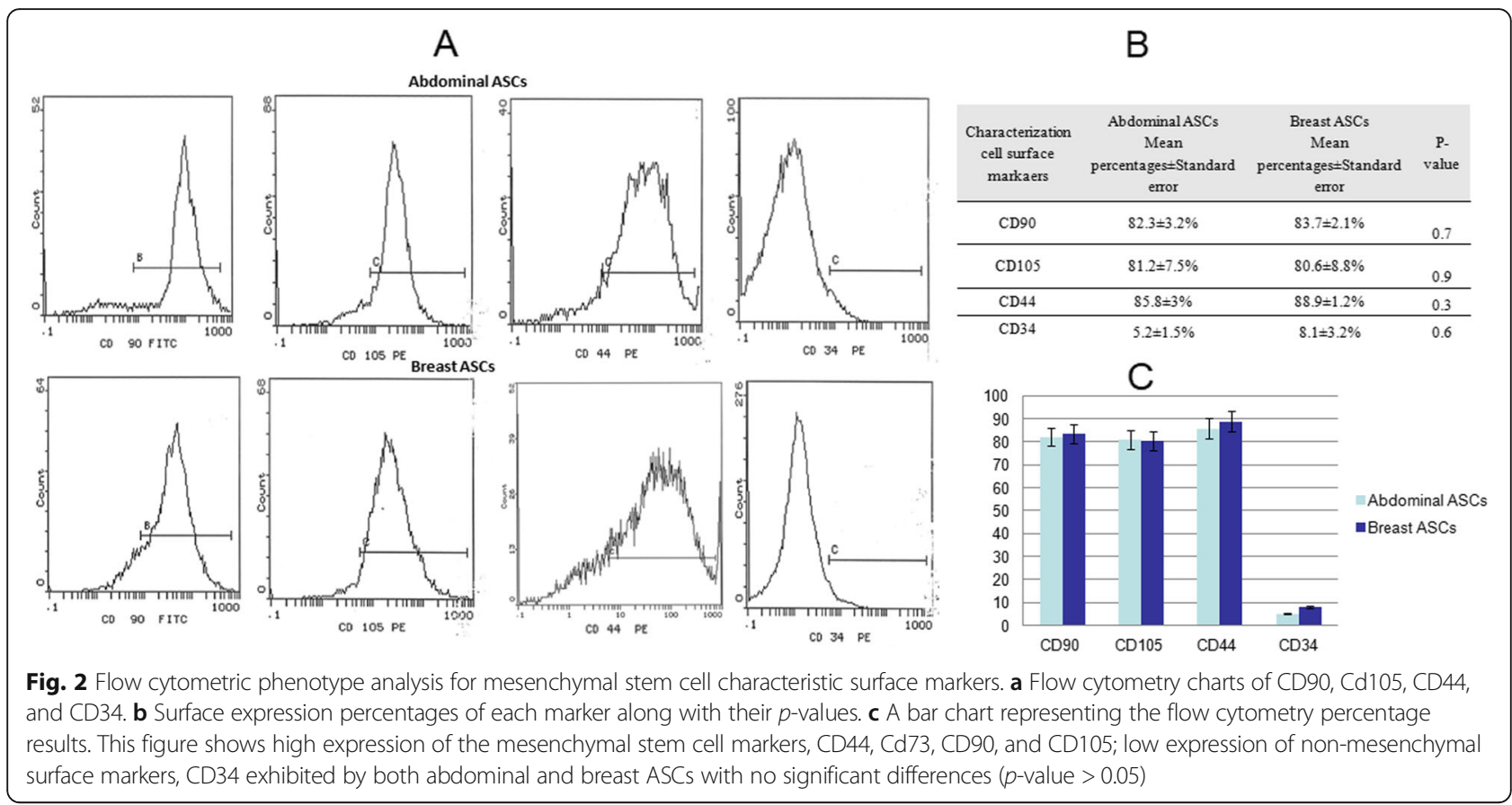

IDO and STAT3 interaction, as well as STAT3 and NAMPT interaction were evidenced by coexpression and automated text-mining. IL-10 and NAMPT and IDO and IL-10 together with IL-10 and Ki67 interactions were proven by automated text-mining only.

Enrichment analysis of our gene set has revealed several significant biological processes with a false discovery rate (FDR) of $<0.01$ as shown in Table 2 including the genes contributing to each biological process (Table 2). Moreover, a number of pathways were significantly enriched for our gene set including FoxO signaling pathway $(\mathrm{FDR}=0.008)$, Jak-STAT signaling pathway $(\mathrm{FDR}=$ 0.009) (KEGG Pathways), IL-10 (FDR =0.006), IL-4 and IL-13 signaling pathways $(F D R=0.011)$ (Reactome Pathways) in which STAT3 and IL-10 are involved.

Functional association gene network prediction was performed using the GeneMANIA server for our differentially upregulated genes in breast versus abdominal ASCs. It provided 20 functionally associated genes with our gene set; these functional associations included coexpression, colocalization, genetic interaction, and sharing common pathways. The 20 genes are demonstrated in Fig. 6 (Supplementary Table 1).

\section{Discussion}

Since the physiological microenvironment of fat depots differs from one anatomical site to another, the biological and functional characteristics of tissue-resident ASCs may vary accordingly. Up to our knowledge, the current study is one of the first comparative studies addressing the immunomodulatory potential in breast versus abdominal ASCs and the first study to compare their antioxidative potentials.

Previously, it has been shown that ASCs characteristics are based on inherent properties as well as microenvironmental factors that vary according to the anatomical region of the adipose tissue (Fuchs et al. 2004; Guneta et al. 2016). Few studies adressing the coparison between breast and abdominal ASCs have been conducted. Some of these studies revealed higher self-renewal capability (Guneta et al. 2016), significant overexpression of FGF2 (Hanson et al. 2013), and higher enrichment in MSCs subpopulation SSEA-4 (Maddox et al. 2012). Meanwhile, some studies have reported similarities between the two types of ASCs in some features such as cell surface phenotype and multilineage differentiation capabilities (Hanson et al. 2013; Maddox et al. 2012; Kim et al. 2013; Choudhery et al. 2015), growth kinetics (Choudhery et al. 2015), impact on macrophage gene expression when cocultured together, and enhancing effect on breast cancer cell line proliferation (Kim et al. 2013). On the other hand, Kim et al. (Kim et al. 2013) reported significant upregulation of the proinflammatory cytokine, IL-1B in abdominal ASCs compared to breast ASCs, while Guneta et al. (Guneta et al. 2016) reported that abdominal ASCs may be better than breast ASCs in cell-assisted fat grafting and adipose tissue turnover, as they demonstrated a higher tendency to adipogenic differentiation in abdominal ASCs than breast-isolated ones.

Using the flow cytometric immunophenotype analysis, the identity of our isolated cells was confirmed to be 

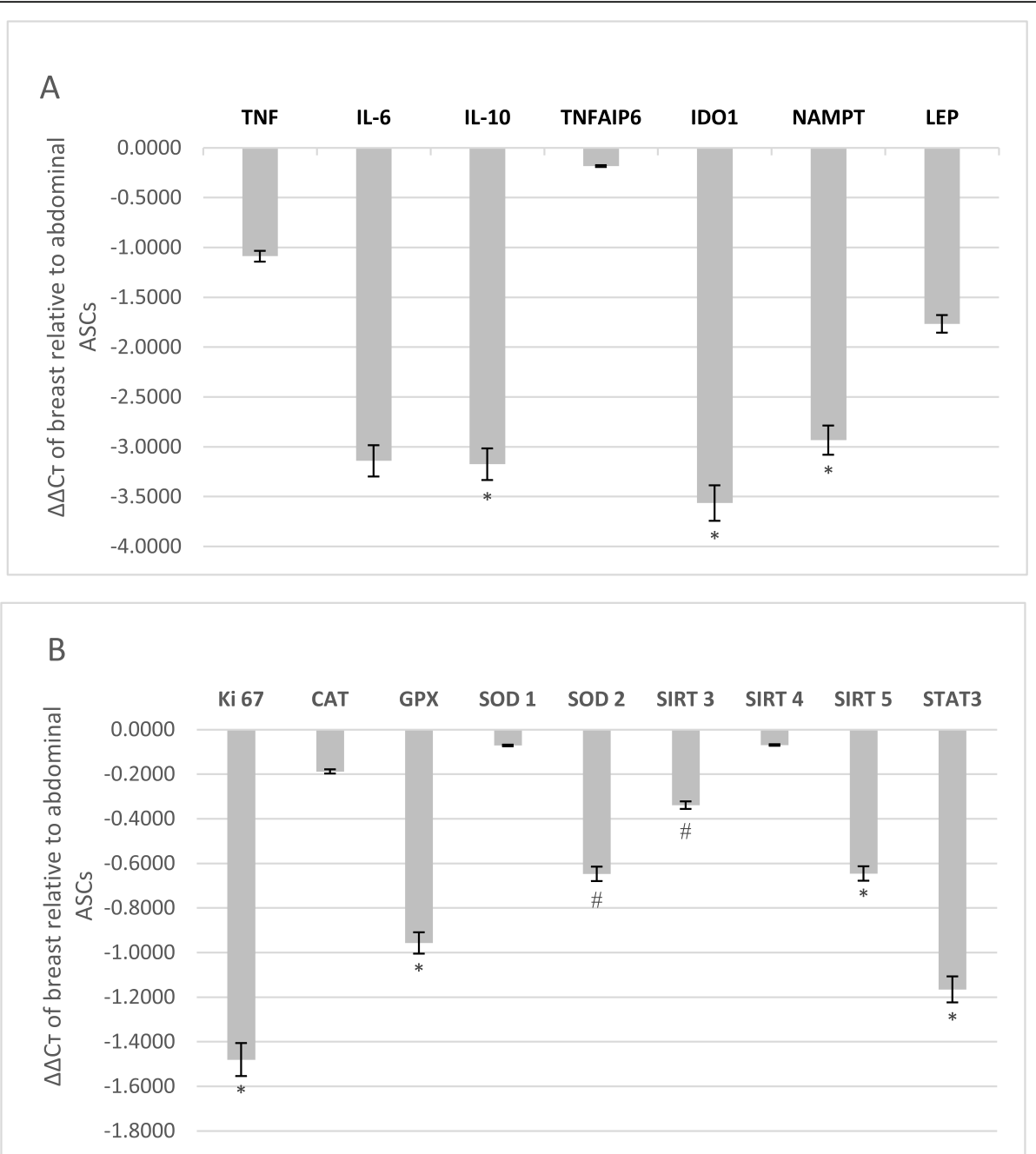

Fig. 3 Gene expression levels. a Gene expression levels of the immunoregulatory cytokines (TNF, IL-10, IL-6, TSG-6, and IDO) and adipokines (leptin and visfatin) in breast compared to abdominal ASCs represented as $\Delta \Delta C_{T}$ values $\left({ }^{*}=p\right.$-value $\left.<0.05\right)$. $\mathbf{b}$ Gene expression levels of the antioxidative markers (SOD1, SOD2, CAT, GPX1, and SIRT3-5), the pluripotency and antioxidative transcription factor (STAT3), and the proliferation marker (Ki67) in breast compared to abdominal ASCs represented as $\Delta \Delta \mathrm{CT}_{\mathrm{T}}$ values $\left({ }^{*}=p\right.$-value $<0.05$ and $\#=p$-value $<0.05$ in 5 samples only)

mesenchymal in origin (non-hematopoietic), where our isolated cells expressed the mesenchymal stem cell markers CD90, CD105, and CD44 with high percentages, while showing low expression of the hematopoietic marker, CD34. In accordance with previous reports (Hanson et al. 2013; Maddox et al. 2012; Guneta et al. 2016; Kim et al. 2013; Choudhery et al. 2015), our study revealed that both breast and abdominal ASCs display MSC characteristic morphology and phenotypic cell surface markers with no significant differences ( $p$-value > 0.05 ) in terms of the expression in both types. Additionally, there was no significant difference in the expression of the investigated immunoregulatory surface markers (CD200, Cd271, CD274, and CD276) between abdominal and breast ASCs ( $p$-value $>0.05)$, indicating that both types of ASCs may have similar direct cell-to-cell immunomodulatory ability.

Investigating the immunomodulatory potential revealed significant overexpression of two potent antiinflammatory mediators, IL-10 and IDO, in breast compared to abdominal ASCs. As previously reported, the immune action demands a balance between pro- and anti-inflammatory responses to accomplish an effective defense against infection while preventing immuneinduced tissue damage. IL-10 and IDO are two major immunoregulatory cytokines through which MSCs contribute to achieving this balance (Couper et al. 2008; Kyurkchiev et al. 2014). IL-10 is considered as a master immune regulator (Couper et al. 2008; Iyer and Cheng 2012) playing a major anti-inflammatory role, thereby 
A

Abdominal ASCs
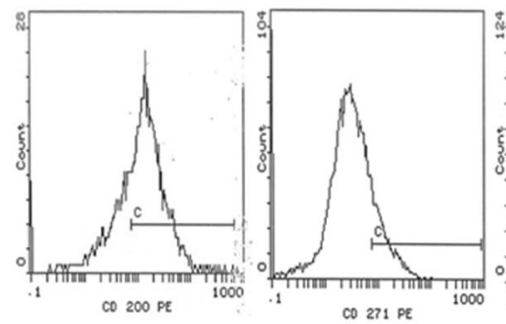

CO $271 \mathrm{PE}$

Breast ASCS
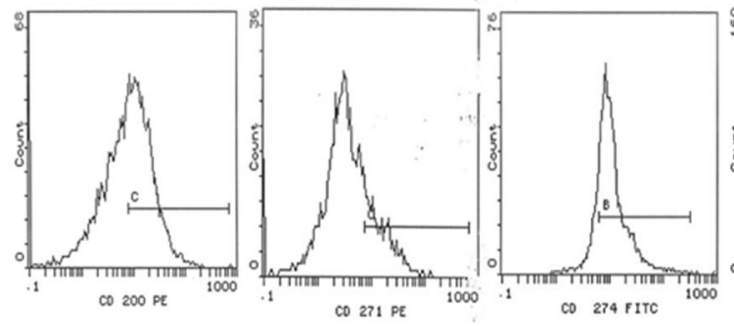

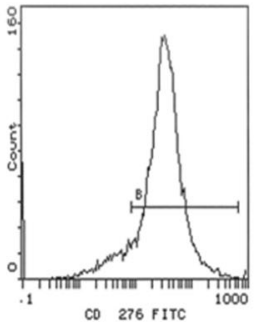

B
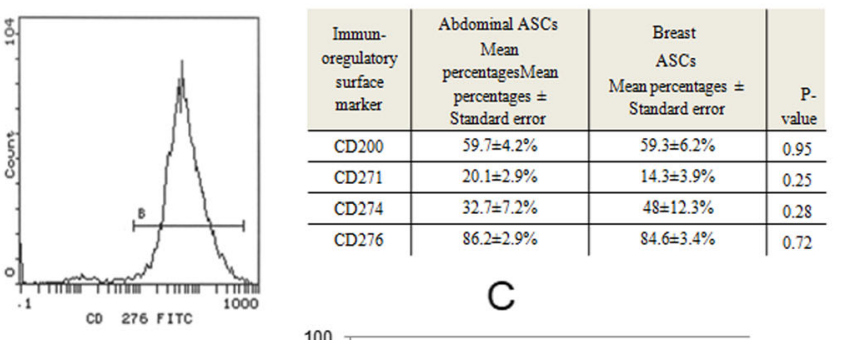

C

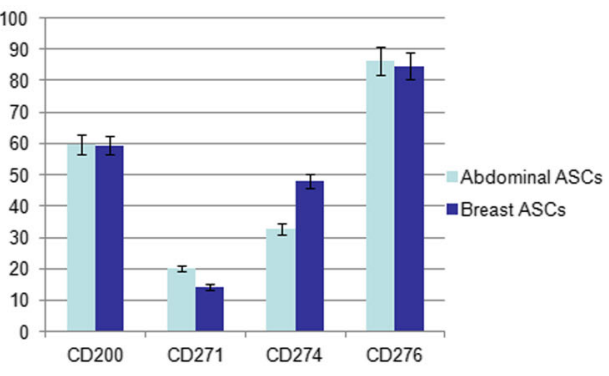

Fig. 4 Flow cytometry of abdominal and breast ASCs for surface expression of immunoregulatory surface markers. a Flow cytometry charts of CD200, CD271, CD274, and CD276. b Surface expression percentages of each marker along with their p-values. $\mathbf{c}$ A bar chart representing the flow cytometry percentage results. Comparable surface expression percentages were observed for both abdominal and breast ASCs as there were no significant differences ( $p$-value $>0.05$ )

preventing tissue damage, induced by inflammatory and autoimmune pathologies. IL-10 contributes to inhibition of proinflammatory cytokine secretion (Kyurkchiev et al. 2014). Our gene expression result for IL-10 is in agreement with that of Kim et al. (Kim et al. 2013) comparative study, who reported also a higher expression for IL-10 in breast ASCs compared to abdominal ASCs. However, their study did not report statistical significance, possibly due to the difference in sample size between the two studies (Kim et al. 2013). IDO is a tryptophan-catabolizing enzyme that is one of the key immunoregulators secreted by MSCs. It mediates the immunosuppressive role of MSCs through catalyzing the degradation of tryptophan to Nformylkynurenine in different immune cells (Kyurkchiev et al. 2014; Chen et al. 2011). IDO inhibits the proliferation and differentiation of $\mathrm{T}$ cells, while stimulating $\mathrm{T}$ regulatory cells to exert their suppressive action (Kyurkchiev et al. 2014; Sharma et al. 2009). Collectively, our findings indicate the superior immunomodulatory potential of breast-derived ASCs over the abdominal ones which may render these cells as attractive tools for therapeutic use in immune-related and inflammatory diseases such as diabetes, nephritis as well as autoimmune diseases, especially in women.

The current study has also revealed a significant upregulation in the expression of the fat-secreted protein, visfatin, in breast compared to abdominal ASCs.
Visfatin adipokine is also known as pre-B cell colonyenhancing factor (PBEF) (Tilg and Moschen 2008; Skoczylas 2009) and cytosolic nicotinamide phosphoribosyltransferase where it takes part in nicotinamide adenine dinucleotide (NAD+) biosynthesis during glucose and lipid metabolism (Skoczylas 2009; Coelho et al. 2013). Visfatin is a multifaceted adipokine that plays various roles in multiple processes such as metabolism, inflammation, cell proliferation, and obesity, as well as having different effects on various diseases. Visfatin exerts hypoglycemic effects by increasing glucose uptake by peripheral tissue and inhibiting its release from the liver (Tilg and Moschen 2008; Kang and Cha 2011; Lee et al. 2015). Importantly, visfatin has been reported to act as an immunomodulatory cytokine (Tilg and Moschen 2008; Garten et al. 2009) playing a dual regulatory role during the inflammation process (Xiao et al. 2015). Therefore, studying the factors that direct the immunomodulatory behavior of visfatin in ASCs is recommended.

Gene expression analysis of TNF, IL-6, and TSG-6 and leptin adipokine demonstrated comparable levels in breast ASCs versus abdominal ones, where there was no statistically significant difference. Our result for TNF and IL-6 expression was similar to that of Kim et al. (Kim et al. 2013), who reported also a statistical similarity in their expression. 


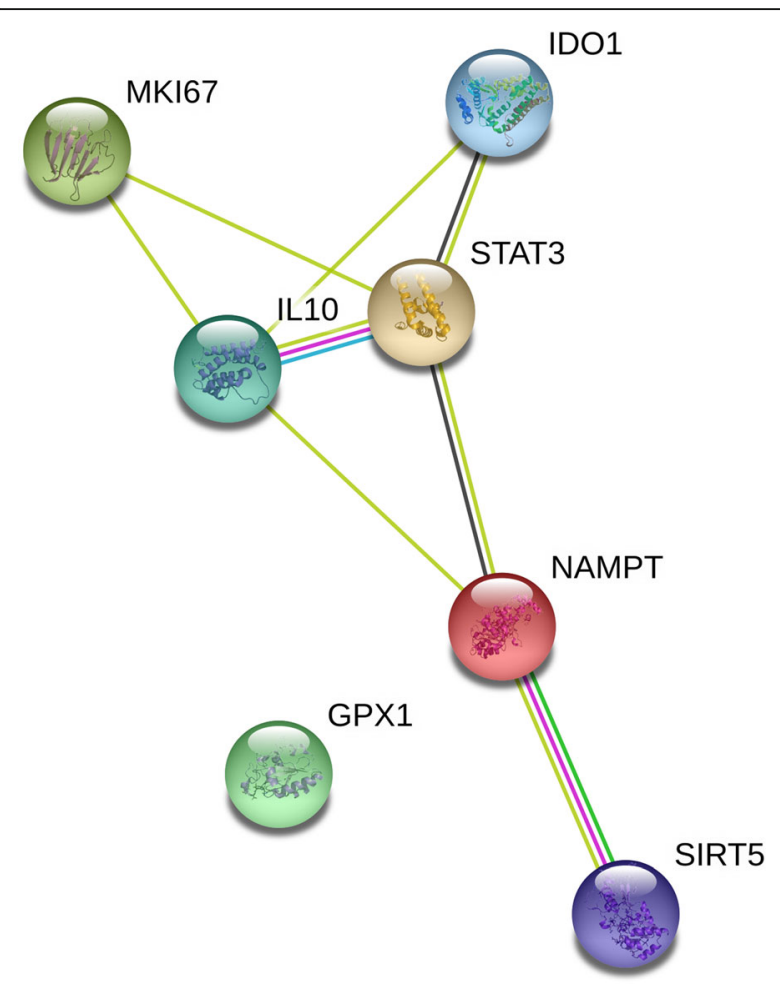

Fig. 5 Protein interaction network for the differentially upregulated gene set in breast ASCs compared to abdominal ASCs as obtained by the STRING database. It shows patterns of interaction between IL10 and STAT3 [experimental (pink line), database annotation (blue line), and automated text-mining (green line)]; NAMPT and SIRT5 [experimental (pink line), automated text-mining (light-green line), and predicted gene neighborhood (dark green line)]; IDO and STAT3 [coexpression (black line) and automated text-mining (light-green line)]; STAT3 and NAMPT [coexpression (black line) and automated text-mining (light-green line)]; IL-10 and NAMPT; IDO and IL-10; STAT3 and Ki67/MKi67; and IL-10 and Ki67/MKi67 [automated textmining only (light-green line)]

To the best of our knowledge, no previous studies compared the antioxidative potentials of breast versus abdominal ASCs. In the current study, the antioxidative capacity of breast versus abdominal ASCs was investigated and our findings demonstrated that breast ASCs adopt an enhanced antioxidative defense mechanism. Significant differences between both ASC populations were found in the expression of a number of antioxidant genes including GPX1, SIRT5, and STAT3. GPX1 was the most significantly upregulated antioxidative gene $(p$ value 0.003$)$. GPX1 is a major member of the GPX family in terms of modulating cellular oxidant stress responses and the regulation of stem cells (Lubos et al. 2011; Jiao et al. 2017). It was previously reported that, by detoxifying hydrogen peroxide and fatty acid hydroperoxides, GPX1 is overexpressed, decreasing the oxidative mitochondrial DNA damage (Legault et al. 2000) and enhancing resistance to oxidant-induced apoptotic cell death (Lubos et al. 2011). SIRT5 is the major mitochondrial desuccinylase (Du et al. 2011) and has been shown to activate SOD1 (Lin et al. 2013). Based on its known antioxidative functions, it is hypothesized that SIRT5 helps in maintaining ROS at low levels to preserve stem cell function and longevity (Denu and Hematti 2016). The survival-promoting transcription factor STAT3 has been shown to exert an antioxidative action (Barry et al. 2009). Activation of STAT3 by different stimuli has been proved to protect ASCs from oxidative stress and enhance their therapeutic potency (Liu et al. 2014; Han et al. 2017). Thus, the significantly elevated upregulation of GPX1, SIRT5, and STAT3 reported here in breast ASC population suggests the possible application of these cells in oxidative stress-linked diseases such as cardiovascular and neurodegenerative diseases, endometriosis, and other gynecological conditions.

A number of studies have monitored the expression of antioxidant defense genes in MSCs at baseline. Valle-Prieto and Conget (Valle-Prieto and Conget 2010) reported that bone marrow MSCs express comparable levels of active forms of CAT, GPX, and SOD; however, others demonstrated that MSCs had lower basal antioxidant activity compared to more differentiated cell types (Orciani et al. 2010; Ko et al. 2011). A recent study, which profiled the expression of pro- and antioxidant genes in human visceral versus subcutaneous ASCs, reported upregulation of genes implicated in antioxidative activities including $\mathrm{XDH}$ and GPX3 and CAT and HMOX1, in most subcutaneous ASC cultures, while oxidative stress-inducing genes such as NOX1, NOX2, NOX3, and NOS3 were higher in visceral ASCs. This indicates the fat depot-specific molecular differences in pro- and antioxidant genes that may underlie depot-specific oxidative stress levels and associated-cell functions (Sriram et al. 2019).

In the current study, SOD2 and SIRT3 were found significantly expressed in most breast ASC samples over abdominal ones. One of the primary functions of SOD2 is to protect mitochondrial DNA against oxidative damage and to keep mitochondrial functions and reliability (Sun et al. 2015; Matsuda et al. 2018). Additionally, Nrf-2 mediated expression of SOD2, among others, was found to protect MSCs from oxidative stress-induced apoptosis and cytotoxicity (Mohammadzadeh et al. 2012). Besides, SIRT3 is the major mitochondrial deacetylase involved in reducing oxidative stress (Denu 2017; Singh et al. 2018). Significantly elevated expression of both SOD2 and SIRT3 of breast ASCs in this study confirms our findings of the superior antioxidative potential of this cell population over abdominal ASCs. Thus, enhanced mitochondrial functions and integrity may be anticipated to be in breast compared to abdominal ASCs. However, this significance was detected in five samples 
Table 2 Biological processes in which our gene list takes part (FDR $<0.01$ ) as obtained by the STRING database

\begin{tabular}{llll}
\hline \#term ID & Biological Process & FDR & Matching proteins in the network \\
\hline GO:2000378 & negative regulation of reactive oxygen species metabolic process & 0.0007 & IL-10, SIRT5, STAT3 \\
GO:0002676 & regulation of chronic inflammatory response & 0.0017 & IDO1, LL-10 \\
GO:0043066 & negative regulation of apoptotic process & 0.0017 & GPX1, IDO1, IL-10, SIRT5, STAT3 \\
GO:0002862 & negative regulation of inflammatory response to antigenic stimulus & 0.0018 & GPX1, IL-10 \\
GO:0070230 & positive regulation of lymphocyte apoptotic process & 0.0035 & IDO1, IL-10 \\
GO:1903427 & negative regulation of reactive oxygen species biosynthetic process & 0.0038 & IL-10, STAT3 \\
GO:0008283 & cell population proliferation & 0.0045 & GPX1, L-10, MKI67, STAT3 \\
GO:0001659 & temperature homeostasis & 0.0046 & GPX1, STAT3 \\
GO:0042127 & regulation of cell population proliferation & 0.0046 & GPX1, IDO1, IL-10, NAMPT, STAT3 \\
GO:1903202 & negative regulation of oxidative stress-induced cell death & 0.0062 & GPX1, LL-10 \\
GO:0050678 & regulation of epithelial cell proliferation & 0.0064 & GPX1, L-10, STAT3 \\
GO:0032655 & regulation of interleukin-12 production & 0.0072 & IDO1, IL-10 \\
GO:0042130 & negative regulation of T cell proliferation & 0.0075 & IDO1, IL-10 \\
GO:0050727 & regulation of inflammatory response & 0.0075 & GPX1, IDO1, IL-10 \\
\hline
\end{tabular}

GO Gene ontology, FDR False discovery rate

only; therefore, larger sample size and SOD2 activity assessment are warranted to confirm these results.

Taken together, our observation of augmented immunomodulatory and antioxidative capacities in breast ASCs over abdominal ASCs may be attributed to the unique dynamic mammary microenvironment and the supportive role that adipose tissue plays, providing endocrine mediators and regulatory signals, throughout the different changes in mammary tissue (Wang et al. 2010; Zwick et al. 2018). Our findings suggest that ASCs contribute to maintaining the immune homeostasis and resisting oxidative stress during the different mammary remodeling and involution cycles and hence preventing any abnormal physiological changes or tumor development.

Ki67 or MKI67 gene expression analysis has shown significant upregulation in breast ASCs compared to abdominal ones. This finding may possibly indicate an enhanced proliferation capacity as $\mathrm{Ki67}$ is a marker associated with cell proliferation and is expressed in different cell cycle phases except for G0 phase (Alicka et al. 2019). This conclusion was supported by Guneta et al.'s (Guneta et al. 2016) findings who compared breast and abdominal fat-derived MSCs in terms of proliferation and clonogenic potential. They reported a significantly higher colony-forming ability and self-renewal potentials for breast ASCs than their abdominal counterparts. In their research, the population doubling analysis of both ASC populations demonstrated that breast fat-derived MSCs grew faster with every population doubling; however, abdominal ASCs showed more growth stability (Guneta et al. 2016). Enhanced proliferation potential of breast ASCs over their abdominal counterparts may be attributed to their superior potential to scavenge ROS avoiding their detrimental effects on cell survival and proliferation at high levels (Jeong and Cho 2015). Furthermore, the dynamic nature of breast tissue, which undergoes repeated cycles of growth and involution along with the supportive role of breast adipose tissue during these physical changes (Zwick et al. 2018), may explain the observed enhanced proliferation potential and fast growth ability of breast ASCs.

Identifying the experimental and predicted proteinprotein interaction networks as well as functionally associated gene networks is essential to understand the cellular processes at the system-level and helps in discovering new aspects for future research (Schwartz et al. 2009). Bioinformatics analysis herein revealed that the members of our significantly upregulated set of genes in breast ASCs versus abdominal ASCs display a high chance of interaction with each other as well as their integrative contribution in several anti-inflammatory/immunoregulatory, antioxidative, and proliferation-related biological processes (Table 2). For example, negative regulation of ROS metabolic process was found to be a significantly enriched biological process $(F D R=0.0007)$ to which IL-10, SIRT5, and STAT3 contribute. In addition, negative regulation of inflammatory response to the antigenic stimulus was significantly enriched (FDR = 0.0018) with the contribution of GPX1 and IL-10. Similarly, the cell population proliferation process was found to be significant $(\mathrm{FDR}=0.0045)$, a process where GPX1, IL-10, Ki67/MKI67, and STAT3 act together. Enrichment analysis also revealed two important signaling pathways: FoxO signaling pathway 


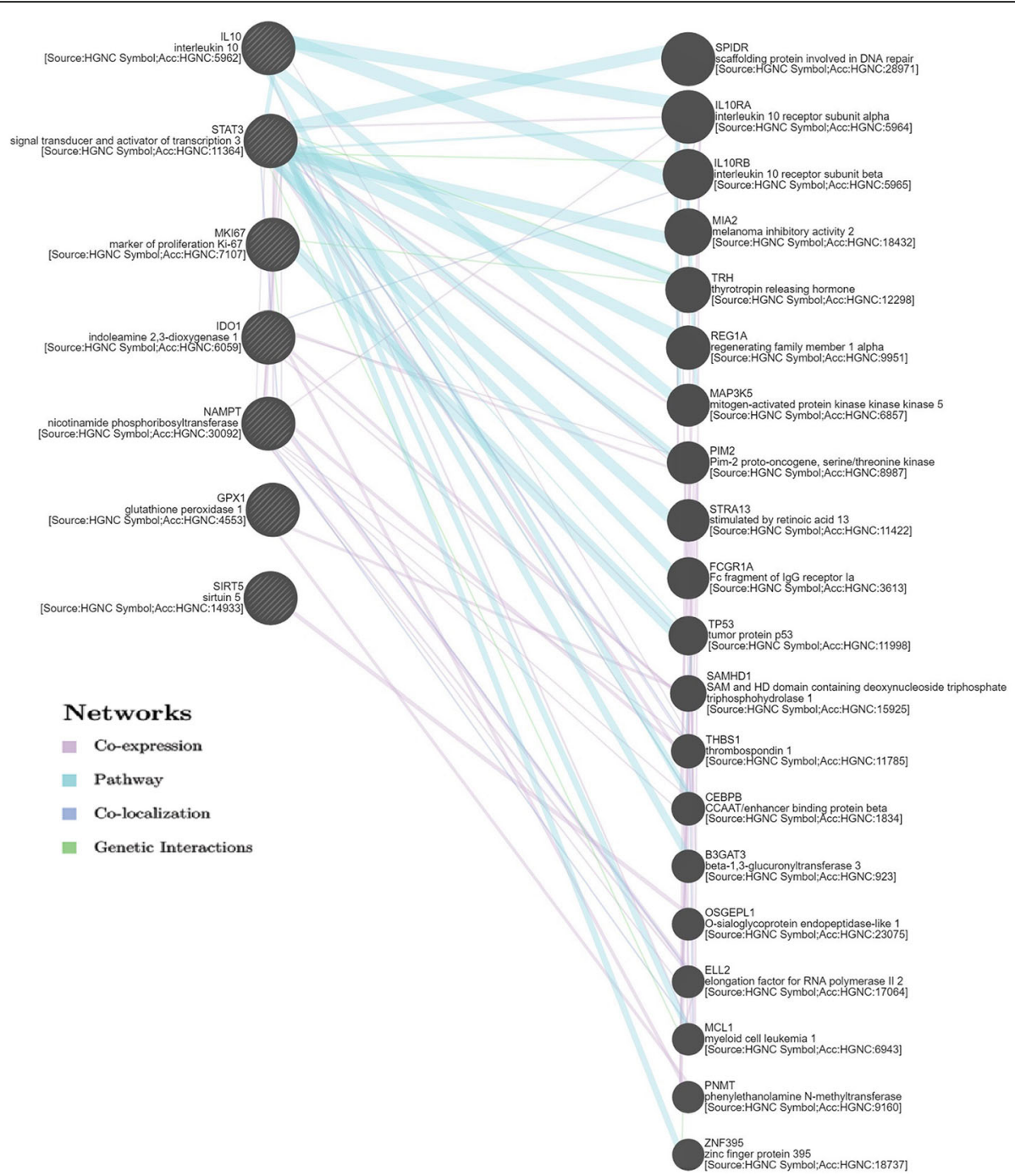

Fig. 6 Functional association gene network as obtained by GeneMANIA server for the significantly upregulated genes in breast ASCs versus abdominal ones. This network includes twenty functionally associated genes that are coexpressed, colocalized, genetically interact, or share the same pathway with our gene set

$(\mathrm{FDR}=0.008)$ and Jak-STAT signaling pathway $(\mathrm{FDR}=0.009)$ which contribute to the self-renewal and regenerative potential of stem cells (Tothova and Gilliland 2007; Lee et al. 2016). Besides, immunosuppressive signaling pathways such as interleukin 10 $(\mathrm{FDR}=0.006)$ and interleukin 4 and interleukin 13 signaling pathways $(F D R=0.011)$ were also significantly enriched (Kucharzik et al. 1998). This indicates the enhancement of these processes in the breast over abdominal ASCs, supporting our experimental results. In addition, twenty genes were computationally predicted to be functionally associated with our gene set, indicating their possible upregulation in breast ASCs and opening the way for further studies concerning their expression and their role in breast ASCs (Fig. 6, Supplementary Table 1).

\section{Conclusions}

From this study, it can be deduced that both breast and abdominal ASCs exhibit similar morphological and phenotypic characteristics; however, breast ASCs exhibit higher proliferative capability as well as superior immunomodulatory and antioxidative potentials compared to abdominal ASCs. These findings may encourage the therapeutic use of breast ASCs especially in autoimmune, inflammatory, and/or oxidative stress-related disorders such as diabetes, endometriosis, cardiovascular diseases and others. However, further in vitro and 
in vivo studies are required to investigate the safety and efficiency of this emerging type of ASCs for use in cellbased therapy.

\section{Supplementary information}

Supplementary information accompanies this paper at https://doi.org/10. 1186/s13619-020-00056-2.

Additional file 1: Supplementary Table 1. Functional association data as obtained by GENEmania database for our input gene set showing the types of functional association between our genes of interest and twenty associated genes.

\section{Abbreviations}

APC: Allophycocyanin; ASCs: Adipose-derived stem cells; CAT: Catalase; CD: Cluster of differentiation; DMEM: Dulbecco's Modified Eagle Medium; DNA: Deoxyribonucleic acid; FBS: Fetal bovine serum; FDR: False discovery rate; FGF-2: Fibroblast growth factor-2; FITC: Fluorescein isocyanate; FOXO: Forkhead box O; GO: Gene ontology; GPX1: Glutathione peroxidase 1; HMox1: Heme oxygenase (decycling) 1; IDO: Indoleamine-2,3-dioxygenase; IL-6, IL-10: Interleukin-6, Interleukin-10; Jak-STAT: Janus Kinase/Signal Transducer and Activator of Transcription.; MKI67: Marker of proliferation ki67; MSCs: Mesenchymal stem cells; NAD: Nicotinamide adenine dinucleotide.; NOS3: Nitric Oxide Synthase 3; NOX1-3: NADPH oxidase 1-3; NrF-2: Nuclear factor erythroid 2-related factor 2; PBEF: Pre-B cell colony-enhancing factor; PBS: Phosphate buffer saline; PE: Phycoerythrin; PPI: Protein-protein interaction; RNA: Ribonucleic acid; ROS: Reactive oxygen species; SIRT35: Sirtuin 3-5; SOD1: Superoxide dismutase 1; SSEA-4: Stage Specific Embryo Antigen-4; STAT3: Signal transducer and activator of transcription 3; TNF: Tumor necrosis factor; TSG-6: TNFa-stimulated gene-6; XDH: Xanthine Dehydrogenase

\section{Authors' contributions}

NA: Designed the study performed the experimental work concerning the immunomodulatory potential analysis studies and the in silico studies, interpretation of data and contributed to writing, organizing, revising and editing the manuscript. MM: Contributed to the study design, performed the experimental work concerning the anti-oxidative potential analysis studies, interpretation of data and contributed to the manuscript writing. MA: performed the statistical analysis for all the obtained results and contributed to the references writing and organization. Both YD and AA were responsible for sample obtaining following the designed inclusion and exclusion criteria. EM: responsible for the experimental supervision and work support. ME: contributed to the in silico analysis and manuscript writing and revising. OA: supervised the whole study, revised and edited the manuscript. All authors read and approved the final manuscript.

\section{Funding}

This work was funded by the National Research Centre, Cairo, Egypt (grant no.11010122), and the Academy of Scientific Research and Technology in Egypt "Jesor initiative" (grant no. 1057).

\section{Availability of data and materials}

All data generated or analyzed during this study are included in this published article and its supplementary information files.

\section{Ethics approval and consent to participate}

The study protocol was approved by the Medical Research Ethics Committee at the National Research Centre, Cairo, Egypt (Registration code: 16-282) and informed consents were obtained.

\section{Competing interests}

All authors declare that they have no competing interest concerning this research article.

\section{Author details}

${ }^{1}$ Stem Cell Research Group, Centre of Excellence for Medical Research, National Research Centre, Cairo, Egypt. ${ }^{2}$ Medical Molecular Genetics Department, Human Genetics and Genome Research Division, National
Research Centre, Cairo 12622, Egypt. ${ }^{3}$ Department of Reproductive Health Research, Medical Research Division. National Research Centre, Cairo, Egypt. ${ }^{4}$ Plastic and Reconstructive Surgery Unit, General Surgery Department, Kasr Al Ainy School of Medicine, Cairo University, Cairo, Egypt. ${ }^{5}$ Biomedical Informatics and Chemoinformatics Group, Centre of Excellence for Medical Research, Informatics and Systems Department, National Research Centre, Cairo, Egypt

Received: 8 May 2020 Accepted: 1 August 2020

Published online: 06 October 2020

\section{References}

Abate N, Garg A, Peshock RM, Stray-Gundersen J, Grundy SM. Relationships of generalized and regional adiposity to insulin sensitivity in men. J Clin Invest. 1995:96(1):88-98.

Alicka M, Major P, Wysocki M, Marycz K. Adipose-derived Mesenchymal stem cells isolated from patients with type 2 diabetes show reduced "Stemness" through an altered Secretome profile, impaired anti-oxidative protection, and mitochondrial dynamics deterioration. J Clin Med. 2019;8(6):765.

Barry SP, Townsend PA, McCormick J, Knight RA, Scarabelli TM, Latchman DS, et al. STAT3 deletion sensitizes cells to oxidative stress. Biochem Biophys Res Commun. 2009:385(3):324-9.

Bunnell BA, Flaat M, Gagliardi C, Patel B, Ripoll C. Adipose-derived stem cells: isolation, expansion and differentiation. Methods. 2008;45(2):115-20.

Chen Y, Zhang J, Lin Y, Lei Q, Guan K, Zhao S, et al. Tumour suppressor SIRT3 deacetylates and activates manganese superoxide dismutase to scavenge ROS. EMBO Rep. 2011;12(6):534-41.

Choudhery MS, Badowski M, Muise A, Pierce J, Harris DT. Subcutaneous adipose tissue-derived stem cell utility is independent of anatomical harvest site. BioRes Open Access. 2015:4(1):131-45.

Coelho M, Oliveira T, Fernandes R. Biochemistry of adipose tissue: an endocrine organ. Arch Med Sci AMS. 2013;9(2):191.

Couper KN, Blount DG, Riley EM. IL-10: the master regulator of immunity to infection. J Immunol. 2008;180(9):5771-7.

Denu RA. SIRT3 enhances mesenchymal stem cell longevity and differentiation. Oxidative Med Cell Longev 2017;2017.

Denu RA, Hematti P. Effects of oxidative stress on mesenchymal stem cell biology. Oxidative Med Cell Longev. 2016;2016.

Du J, Zhou Y, Su X, Yu JJ, Khan S, Jiang H, et al. Sirt5 is a NAD-dependent protein lysine demalonylase and desuccinylase. Science. 2011;334(6057):806-9.

Fathi E, Farahzadi R. Zinc Sulphate Mediates the Stimulation of Cell Proliferation of Rat Adipose Tissue-Derived Mesenchymal Stem Cells Under High Intensity of EMF Exposure. Biol Trace Elem Res. 2018;184(2):529-35 Available from: https://doi.org/10.1007/s12011-017-1199-4 [cited 202022 Jun].

Fathi E, Farahzadi R, Sheikhzadeh N. Immunophenotypic characterization, multilineage differentiation and aging of zebrafish heart and liver tissue-derived mesenchymal stem cells as a novel approach in stem cell-based therapy. Tissue Cell. 2019 Apr:57:15-21.

Franz M, Rodriguez H, Lopes C, Zuberi K, Montojo J, Bader GD, et al. GeneMANIA update 2018. Nucleic Acids Res. 2018;46(Web Server issue):W60-4 Available from: https:// muw.ncbi.nlm.nih.gov/pmc/articles/PMC6030815/ [cited 202020 Jan].

Fuchs E, Tumbar T, Guasch G. Socializing with the neighbors: stem cells and their niche. Cell. 2004;116(6):769-78.

Garten A, Petzold S, Körner A, Imai S, Kiess W. Nampt: linking NAD biology, metabolism and cancer. Trends Endocrinol Metab. 2009;20(3):130-8.

Gimble JM, Katz AJ, Bunnell BA. Adipose-derived stem cells for regenerative medicine. Circ Res. 2007;100(9):1249-60.

Guneta V, Tan NS, Sugii S, Lim TC, Wong TCM, Choong C. Comparative study of adiposederived stem cells from abdomen and breast. Ann Plast Surg. 2016;76(5):569-75.

Han D, Li X, Fan W-S, Chen J-W, Gou T-T, Su T, et al. Activation of cannabinoid receptor type II by AM1241 protects adipose-derived mesenchymal stem cells from oxidative damage and enhances their therapeutic efficacy in myocardial infarction mice via Stat3 activation. Oncotarget. 2017:8(39):64853.

Han S, Sun HM, Hwang K-C, Kim S-W. Adipose-derived stromal vascular fraction cells: update on clinical utility and efficacy. Crit Rev Eukaryot Gene Expr. 2015;25(2).

Hanson SE, Kim J, Hematti P. Comparative analysis of adipose-derived mesenchymal stem cells isolated from abdominal and breast tissue. Aesthet Surg J. 2013;33(6):888-98.

lyer SS, Cheng G. Role of interleukin 10 transcriptional regulation in inflammation and autoimmune disease. Crit Rev Immunol. 2012;32(1). 
Jeong S-G, Cho G-W. Endogenous ROS levels are increased in replicative senescence in human bone marrow mesenchymal stromal cells. Biochem Biophys Res Commun. 2015;460(4):971-6.

Jiao Y, Wang Y, Guo S, Wang G. Glutathione peroxidases as oncotargets. Oncotarget. 2017:8(45):80093.

Jurgens WJ, Oedayrajsingh-Varma MJ, Helder MN, ZandiehDoulabi B, Schouten TE, Kuik DJ, et al. Effect of tissue-harvesting site on yield of stem cells derived from adipose tissue: implications for cell-based therapies. Cell Tissue Res. 2008;332(3):415-26

Kang YS, Cha DR. The role of visfatin in diabetic nephropathy. Chonnam Med J. 2011;47(3):139-43.

Kim J, Escalante LE, Dollar BA, Hanson SE, Hematti P. Comparison of breast and abdominal adipose tissue mesenchymal stromal/stem cells in support of proliferation of breast cancer cells. Cancer Investig. 2013;31(8):550-4.

Kim Y, Jo S, Kim WH, Kweon O-K. Antioxidant and anti-inflammatory effects of intravenously injected adipose derived mesenchymal stem cells in dogs with acute spinal cord injury. Stem Cell Res Ther. 2015;6(1):229.

Ko E, Lee KY, Hwang DS. Human umbilical cord blood-derived mesenchymal stem cells undergo cellular senescence in response to oxidative stress. Stem Cells Dev. 2011;21(11):1877-86

Kucharzik T, LÜgering N, Pauels H-G, Domschke W, Stoll R. IL-4, IL-10 and IL-13 down-regulate monocyte-chemoattracting protein-1 (MCP-1) production in activated intestinal epithelial cells. Clin Exp Immunol. 1998;111(1):152-7 Available from: https://www.ncbi.nlm.nih.gov/pmc/ articles/PMC1904856/ [cited 202020 Jan].

Kyurkchiev D, Bochev I, Ivanova-Todorova E, Mourdjeva M, Oreshkova T, Belemezova K, et al. Secretion of immunoregulatory cytokines by mesenchymal stem cells. World J Stem Cells. 2014;6(5):552

Lee JO, Kim N, Lee HJ, Lee YW, Kim JK, Kim HI, et al. Visfatin, a novel adipokine, stimulates glucose uptake through the Ca2+-dependent AMPK-p38 MAPK pathway in C2C12 skeletal muscle cells. J Mol Endocrinol. 2015;54(3):251-62

Lee SC, Jeong HJ, Lee SK, Kim S-J. Hypoxic Conditioned Medium From Human Adipose-Derived Stem Cells Promotes Mouse Liver Regeneration Through JAK/STAT3 Signaling. STEM CELLS Transl Med. 2016;5(6):816-25 Available from: https://stemcellsjournals.onlinelibrary.wiley.com/doi/abs/10.5966/sctm.2 015-0191 [cited 202020 Jan].

Legault J, Carrier C, Petrov P, Renard P, Remacle J, Mirault M-E. Mitochondrial GPX1 decreases induced but not basal oxidative damage to mtDNA in T47D cells. Biochem Biophys Res Commun. 2000;272(2):416-22.

Leto Barone AA, Khalifian S, Lee W, Brandacher G. Immunomodulatory effects of adipose-derived stem cells: fact or fiction? Biomed Res Int 2013;2013.

Liang X, Ding Y, Zhang Y, Tse H-F, Lian Q. Paracrine Mechanisms of Mesenchymal Stem Cell-Based Therapy: Current Status and Perspectives. Cell Transplant. 2014;23(9):1045-1059. Available from: https://doi.org/10.3727/ $096368913 \times 667709$ [cited 201929 Dec].

Lin Z-F, Xu H-B, Wang J-Y, Lin Q, Ruan Z, Liu F-B, et al. SIRT5 desuccinylates and activates SOD1 to eliminate ROS. Biochem Biophys Res Commun. 2013;441(1):191-5.

Liu J, Wang H, Wang Y, Yin Y, Du Z, Liu Z, et al. The stem cell adjuvant with Exendin-4 repairs the heart after myocardial infarction via STAT 3 activation. $J$ Cell Mol Med. 2014;18(7):1381-91.

Livak KJ, Schmittgen TD. Analysis of relative gene expression data using real-time quantitative $P C R$ and the 2- $\Delta \Delta C T$ method. Methods. 2001:25(4):402-8.

Locke M, Windsor J, Dunbar PR. Human adipose-derived stem cells: isolation, characterization and applications in surgery. ANZ J Surg. 2009;79(4):235-44.

Lubos E, Loscalzo J, Handy DE. Glutathione peroxidase-1 in health and disease: from molecular mechanisms to therapeutic opportunities. Antioxid Redox Signal. 2011;15(7):1957-97.

Maddox JR, Ludlow KD, Li F, Niyibizi C. Breast and abdominal adipose multipotent mesenchymal stromal cells and stage-specific embryonic antigen 4 expression. Cells Tissues Organs. 2012;196(2):107-16.

Maria AT, Toupet K, Bony C, Pirot N, Vozenin M, Petit B, et al. Antifibrotic, antioxidant, and immunomodulatory effects of mesenchymal stem cells in HOCl-induced systemic sclerosis. Arthritis Rheumatol. 2016;68(4):1013-25.

Matsuda S, Nakagawa Y, Kitagishi Y, Nakanishi A, Murai T. Reactive oxygen species, superoxide dimutases, and PTEN-p53-AKT-MDM2 signaling loop network in mesenchymal stem/stromal cells regulation. Cells. 2018;7(5):36.

Mizuno $\mathrm{H}$, Tobita M, Uysal AC. Concise review: adipose-derived stem cells as a novel tool for future regenerative medicine. Stem Cells. 2012;30(5):804-10.

Mohammadzadeh M, Halabian R, Gharehbaghian A, Amirizadeh N, JahanianNajafabadi A, Roushandeh AM, et al. Nrf-2 overexpression in mesenchymal stem cells reduces oxidative stress-induced apoptosis and cytotoxicity. Cell Stress Chaperones. 2012;17(5):553-65.

Nepali S, Park M, Lew H, Kim O. Comparative analysis of human adipose-derived Mesenchymal stem cells from orbital and abdominal fat. Stem Cells Int. 2018;2018.

O'Halloran N, Courtney D, Kerin MJ, Lowery AJ. Adipose-derived stem cells in novel approaches to breast reconstruction: their suitability for tissue engineering and oncological safety. Breast Cancer Basic Clin Res. 2017;11: 1178223417726777

Orciani M, Gorbi S, Benedetti M, Di Benedetto G, Mattioli-Belmonte M, Regoli F, et al. Oxidative stress defense in human-skin-derived mesenchymal stem cells versus human keratinocytes: different mechanisms of protection and cell selection. Free Radic Biol Med. 2010;49(5):830-8.

Orgun D, Mizuno H. Multipotency and secretome: the mechanisms behind the regenerative potential of adipose-derived stem cells. Plast Aesthetic Res. 2017:4:32.

Padoin AV, Braga-Silva J, Martins P, Rezende K, da Rosa Rezende AR, Grechi B, et al. Sources of processed lipoaspirate cells: influence of donor site on cell concentration. Plast Reconstr Surg. 2008;122(2):614-8.

Rezai Rad M, Bohloli M, Akhavan Rahnama M, Anbarlou A, Nazeman P, Khojasteh A. Impact of tissue harvesting sites on the cellular behaviors of adiposederived stem cells: implication for bone tissue engineering. Stem Cells Int. 2017;2017.

Russo V, Yu C, Belliveau P, Hamilton A, Flynn LE. Comparison of human adiposederived stem cells isolated from subcutaneous, omental, and intrathoracic adipose tissue depots for regenerative applications. Stem Cells Transl Med. 2014;3(2):206-17.

Schipper BM, Marra KG, Zhang W, Donnenberg AD, Rubin JP. Regional anatomic and age effects on cell function of human adipose-derived stem cells. Ann Plast Surg. 2008;60(5):538-44 Available from: https://www.ncbi.nlm.nih.gov/ pubmed/18434829.

Schwartz AS, Yu J, Gardenour KR, Finley RL, Ideker T. Cost-effective strategies for completing the interactome. Nat Methods. 2009;6(1):55-61.

Scutiero G, lannone P, Bernardi G, Bonaccorsi G, Spadaro S, Volta CA, et al. Oxidative stress and endometriosis: a systematic review of the literature. Oxidative Med Cell Longev 2017;2017:7265238.

Sharma MD, Hou D-Y, Liu Y, Koni PA, Metz R, Chandler P, et al. Indoleamine 2,3dioxygenase controls conversion of Foxp3+ Tregs to TH17-like cells in tumor-draining lymph nodes. Blood. 2009;113(24):6102-11.

Singh CK, Chhabra G, Ndiaye MA, Garcia-Peterson LM, Mack NJ, Ahmad N. The role of sirtuins in antioxidant and redox signaling. Antioxid Redox Signal. 2018;28(8):643-61.

Skoczylas A. The role of visfatin in the pathophysiology of human. Wiadomosci Lek Wars Pol 1960. 2009;62(3):190-196.

Sriram S, Yuan C, Chakraborty S, Tay W, Park M, Shabbir A, et al. Oxidative stress mediates depot-specific functional differences of human adipose-derived stem cells. Stem Cell Res Ther. 2019;10(1):141.

Sun J, Ren X, Simpkins JW. Sequential upregulation of superoxide dismutase 2 and heme oxygenase 1 by tert-butylhydroquinone protects mitochondria during oxidative stress. Mol Pharmacol. 2015;88(3):437-49.

Szklarczyk D, Gable AL, Lyon D, Junge A, Wyder S, Huerta-Cepas J, et al. STRING v11: protein-protein association networks with increased coverage, supporting functional discovery in genome-wide experimental datasets. Nucleic Acids Res. 2019;47(D1):D607-13.

Tchkonia T, Thomou T, Zhu Y, Karagiannides I, Pothoulakis C, Jensen MD, et al. Mechanisms and metabolic implications of regional differences among fat depots. Cell Metab. 2013;17(5):644-56.

Tilg $H$, Moschen AR. Role of adiponectin and PBEF/visfatin as regulators of inflammation: involvement in obesity-associated diseases. Clin Sci. 2008:114(4):275-88.

Tothova Z, Gilliland DG. FoxO Transcription Factors and Stem Cell Homeostasis: Insights from the Hematopoietic System. Cell Stem Cell. 2007;1(2):140-52 Available from: https://www.cell.com/cell-stem-cell/abstract/S1934-5 909(07)00083-5 [cited 202020 Jan]..

Uttara B, Singh AV, Zamboni P, Mahajan RT. Oxidative Stress and Neurodegenerative Diseases: A Review of Upstream and Downstream Antioxidant Therapeutic Options. Curr Neuropharmacol [Internet]. 2009 Mar [cited 2019 Dec 29];7(1):65-74. Available from: https://www.ncbi.nlm.nih.gov/ pmc/articles/PMC2724665/.

Valle-Prieto A, Conget PA. Human mesenchymal stem cells efficiently manage oxidative stress. Stem Cells Dev. 2010;19(12):1885-93. 
Waki H, Tontonoz P. Endocrine functions of adipose tissue. Annu Rev Pathol Mech Dis. 2007:2:31-56.

Wang X, Reagan MR, Kaplan DL. Synthetic adipose tissue models for studying mammary gland development and breast tissue engineering. J Mammary Gland Biol Neoplasia. 2010;15(3):365-76.

Wronska A, Kmiec Z. Structural and biochemical characteristics of various white adipose tissue depots. Acta Physiol. 2012;205(2):194-208.

Xiao K, Zou W-H, Yang Z, Rehman ZU, Ansari AR, Yuan H-R, et al. The role of visfatin on the regulation of inflammation and apoptosis in the spleen of LPS-treated rats. Cell Tissue Res. 2015;359(2):605-18.

Yang J, Xiong L, Wang R, Sun J, Hirche C. Adipose-derived stem cells from the breast. J Res Med Sci Off J Isfahan Univ Med Sci. 2014;19(2):112.

Zuk PA, Zhu M, Mizuno H, Huang J, Futrell JW, Kaz A, et al. Multilineage cells from human adipose tissue: implications for cell-based therapies. Tissue Eng. 2001;7(2):21128.

Zwick RK, Guerrero-Juarez CF, Horsley V, Plikus MV. Anatomical, physiological, and functional diversity of adipose tissue. Cell Metab. 2018;27(1):68-83.

\section{Submit your manuscript to a SpringerOpen ${ }^{\odot}$ journal and benefit from:}

- Convenient online submission

- Rigorous peer review

- Open access: articles freely available online

High visibility within the field

- Retaining the copyright to your article

Submit your next manuscript at $\boldsymbol{\nabla}$ springeropen.com 